\title{
Clothing Comfort- Physiological Status and Psychological Status
}

Lavanya S

Army Institute of Fashion and Design, AssistantProfessor, Fashion Design, Kothanur Post, Nagareshwara, Nagenahalli, Bengaluru, Karnataka 560077

To Cite this Article

Lavanya S, "Clothing Comfort- Physiological Status and Psychological Status", International Journal for Modern Trends in Science and Technology, 6(9S): 61-67, 2020.

Article Info

Received on 25-August-2020, Revised on 08-September-2020, Accepted on 12-September-2020, Published on 18-September-2020.

\section{ABSTRACT}

The primary need of people to dress has changed as time passed, because different high-tech fibers, yarns, fabrics, finishing applications, trends and society influences have completely changed. Welfare and comfort properties have become decisive components to make a product appreciated and successful. This paper presents the detailed explanation of clothing comfort, its subgroups and also the Physiological status and psychological status of the people.

Clothing also known as clothes, apparel and attire is items worn on the body. Clothing is typically made of fabrics or textiles but over time has included garments made from animal skin or other thin layers of materials put together. The wearing of comfort clothing is mostly restricted to human beings and is a feature of all human societies. Comfort or being comfortable is a sense of physical or psychological ease, often characterized as a lack of hardship. Persons who are lacking in comfort are uncomfortable, or experiencing discomfort. A degree of psychological comfort can be achieved by recreating experiences that are associated with pleasant. Persons who are surrounded with things that provide psychological comfort may be described as being "in their comfort zone". Because of the personal nature of positive associations, psychological comfort is highly subjective. As the year goes the word comfort is been used in all areas such as food, work, people and clothing.

Thermal comfort is the condition of mind that expresses satisfaction with the thermal environment and is assessed by subjective evaluation. The human body will release excess heat into the environment, so the body can continue to operate. The heat transfer is proportional to temperature difference. Maintaining this standard of thermal comfort for occupants is one of the important goals of HVAC (heating, ventilation, and air conditioning) design engineers. And in designing of clothes is the most important goal of a fashion designer.

There are six primary factors that directly affect thermal comfort that can be grouped in two categories: personal factors - because they are characteristics of the occupants - and environmental factors - which are conditions of the thermal environment. The former are metabolic rate and clothing level, the latter are air temperature, mean radiant temperature, air speed and humidity. Even if all these factors may vary with time, standards usually refer to a steady state to study thermal comfort, just allowing limited temperature variations.

The study was conducted to know the responses about comfort clothing in Physiological status and psychological status acceptance. Since there are large variations from person to person in terms of physiological and psychological satisfaction, it is hard to find an optimal temperature for everyone in a 
given space. Survey is been collected to define conditions that will be found comfortable for a specified percentage of occupants, being comfortable is a sense of physical or psychological factors.

Understanding clothing comfort, Need and consumer trends basic and universal need of consumers in clothing is comfort and they look for good feel and comfort when they buy clothing and other textile materials. Clothing is very important in our life that we use every day to obtain physiological and psychological comfort and also to ensure physical conditions around our body suitable for survival. Therefore, it is extremely important for the survival of human beings and improvement of the quality of our life to have good understanding of the fundamentals of clothing comfort. From the viewpoint of the manufacturers of clothing and textile materials, understanding of clothing comfort has substantial financial implications in the effort to satisfy the needs and wants of consumers in order to obtain sustainable competitive advantages in modern consumer markets. Consumer always expects some additional functional qualities from the clothes they purchase. Clothing is manufactured in a wide range of thermal, tactile and physical properties to meet consumer needs. Depending on the nee. and expectations of the consumer's, the clothing and textile manufacturers provide wide range of options to enhance human comfort. For example, clothing made from blends and natural fibres are preferred to man-made fibres for all comfort attributes except smoothness or woven fabric are preferred to knits for smoothness, thickness and openness. To understand the basics of clothing comfort, sensory tools as well as the equipment's to evaluate the comfort related characteristics of textile materials have been developed. Large number of studies has been carried out and many equipment are developed in the textile and clothing area such as mechanical, thermal and surface testing, so as to evaluate the related physical properties, but the body between measurement and the consumer feeling of comfort are still difficult to establish.

Consumers want everything from the clothing, i.e. it should look good, feel good, perform well, said like their clothing to match with their chosen attitudes, roles and images. Consumers are now allowing touch, smell, intuition, and emotion to influence their decision on clothing selection more than their aesthetic sense. Asa result, great importance is being attributed to the wearing experience and thus comfort is being reinforced as a key parameter in clothing. It is also true that requirements of consumers on comfort changes with products and situations. Clearly, understanding and satisfying the needs of consumer towards clothing products are crucial for the long-term survival and growth of clothing and textile demand. Understanding and enhancement of clothing comfort is definitely one of the important issues.

\section{INTRODUCTION}

The basic needs of human are food, clothing and shelter. After fulfilling the first need of food, a person looks for the second important need, i.e. clothing. In the present-day society, we expect much more from clothing than to satisfy our basic need. In most societies the clothing is for the purpose of expressing wealth, status, occupation, age, occasion, gender, etc [1]. There are various factors which influence the selection of clothing type.

It is evident from Fig. 1 that the factors which influence the selection of clothing can be divided broadly into four major groups, i.e. social factor, economic factor, environmental factor and physical factor. All these factors play significant roles in selection of clothing of a person. The social factors include the place where a person lives (urban or rural area), cultural background of person, gender, occupation, occasion, social status, etc. Depending on the place where a person lives, the clothing pattern changes. In urban area, due to close cultural interactions between the various sections of people, the clothing pattern becomes more cosmopolitan in nature. But on the other hand, the rural clothing is more influenced by the regional factors. Similarly, clothing is also influenced by cultural background and upbringing of a pesos. The upbringing influences the taste of a person toward the clothing significantly. The modern society does not believe in gender biasness and strongly oppose this. But, are we ready to accept this to be applied while selecting clothing? Except few exceptions, we are still comfortable in maintaining differences in male and female clothing. In some cases, a person selects his clothing depending on the occupational requirement. For example, one can easily make out the difference between police and a common man depending on his clothing, or in a hospital a nurse can be easily identified based on her clothing. We generally prefer to wear different clothing depending on the occasion, namely formal wear, casual wear, etc. A person generally prefers to wear 
formal clothing in office, but the same person prefers casual wear in leisure trip. It is also very common that a person tries to show his social status through clothing, this trend prevails in every society since the beginning of the civilization. The kings always tried to differentiate themselves from the common man by wearing royal clothing.[5]

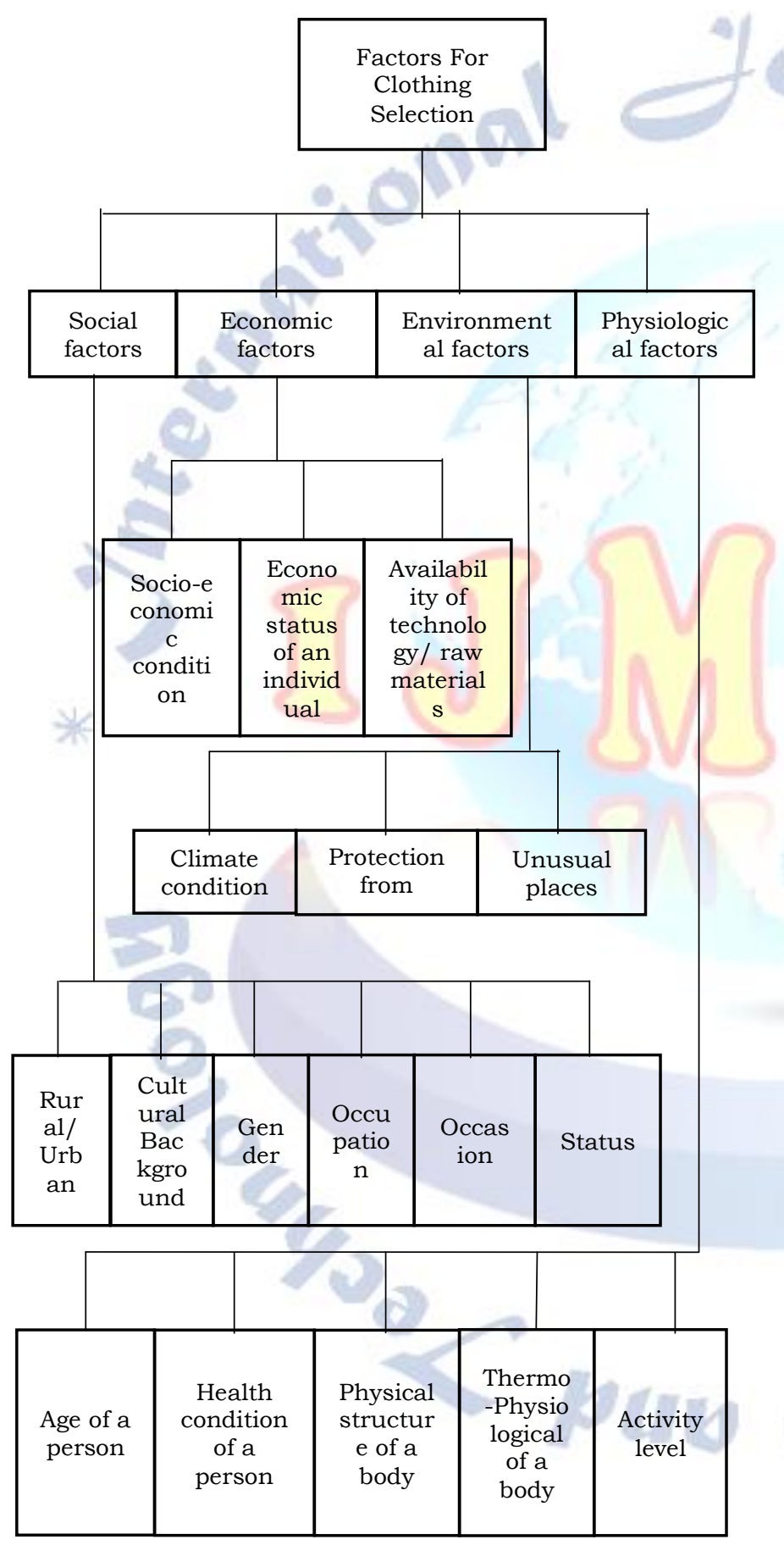

Figure 1

It is evident from Fig. 1 that the factors which influence the selection of clothing can be divided broadly into four major groups, i.e. social factor, economic factor, environmental factor and physical factor. All these factors play significant roles in selection of clothing of a person. The social factors include the place where a person lives (urban or rural area), cultural background of person, gender, occupation, occasion, social status, etc. Depending on the place where a person lives, the clothing pattern changes. In urban area, due to close cultural interactions between the various sections of people, the clothing pattern becomes more cosmopolitan in nature. But on the other hand, the rural clothing is more influenced by the regional factors. Similarly, clothing is also influenced by cultural background and upbringing of a pesos. The upbringing influences the taste of a person toward the clothing significantly. The modern society does not believe in gender biasness and strongly oppose this. But, are we ready to accept this to be applied while selecting clothing? Except few exceptions, we are still comfortable in maintaining differences in male and female clothing. In some cases, a person selects his clothing depending on the occupational requirement. For example, one can easily make out the difference between police and a common man depending on his clothing, or in a hospital a nurse can be easily identified based on her clothing. We generally prefer to wear different clothing depending on the occasion, namely formal wear, casual wear, etc. A person generally prefers to wear formal clothing in office, but the same person prefers casual wear in leisure trip. It is also very common that a person tries to show his social status through clothing, this trend prevails in every society since the beginning of the civilization. The kings always tried to differentiate themselves from the common man by wearing royal clothing. [5]

Among the economic factors the important components are economic condition of society, economic status individual and availability of technology or raw material. When the economic condition of society changes that also reflects through clothing. It is well-know fact that the general clothing pattern of rich and poor sectors of society differs and it is obvious. This is also true for individual. Each individual selects clothing depending on the affordability. Person also selects clothing to show his economic status. The availability of a particular type of clothing depends mainly on the availability of technology and raw materials. These two factors are directly or indirectly dependent on the economic situation and affordability of the society. The environmental factors include climatic conditions (too cold, too hot, raining, chilled wind, etc.), protection from 
extreme environment, unusual places (space or underwater), etc. Depending on the environmental conditions the clothing need changes. Her, the performance factors are the dominating parameters. One requires different clothing for different climatic conditions. [4] A person, going to extreme cold place, will definitely like to protect himself from extreme cold by wearing extreme cold protecting clothing. But the same person will not use the same clothing in normal environment. Depending on the climatic temperature the garments are broadly divided into two categories, namely winter wear and summer wear. Similarly, in rainy days we require clothing which is waterproof. Clothing pattern also changes depending on the environmental threat, like explosives, poisons, biological attacks, fire, radioactive or ultraviolet rays, etc. Clothing also has to withstand falling and flying objects in certain circumstances. Depending on the needs of unusual places, like deep under sea, space etc., the type of clothing changes. In these places the special type clothing is required for protection and specific performance. The last and very important factor is physical conditions of a person, which include age, condition of health of person, body structure, physiological response of body, activity level, etc. The clothing pattern changes with the age of person due to the psychological and physiological changes with time. A child needs different type of clothing than an aged person. Similarly, the clothing need also changes with the physical health of a person. Someone with specific problem with a particular fibre, like allergy, irritation, would like to avoid wearing that particular clothing made with these fibres. Clothing selection also depends on the physical built of body, i.e. whether fat or thin, tall or short, etc. Person with special physical need may require specific clothing. Physiological response of body varies widely from person to person and so does the clothing need. $\mathrm{M}$ a given environmental condition a particular person may feel colder or heat or sweat than others. This is due to the fact that the thermo-physiological responses are different for different persons. The selection of clothing also depends on the level of activity of a person. Under heavy activity the human body generates more heat and sweat. The clothing, he wears, should be able to dissipate and transmit the heat and sweat quickly to keep the body heat under control. A sports person needs special sportswear depending on the type of sports or a worker needs specific work wear depending on his activity. People in challenging activities and sports coulduse smart clothing, that is, clothing that can sense the wearer's condition or situation and, in turn, modify its own structure to protect him or her, for example to keep the body warm or cool. A very well-known proverb says that "There is no such thing as bad weather, only bad clothing". Textiles always have played important roles in well-being of a human being by protecting it from different adverse environmental conditions and making him feel comfortable. Comfort characteristic is an important functionality of clothing. Human thermo-physiological comfort is associated with the thermal balance of human body, which is highly dependent on metabolism rate, physical activities, ambient temperature, and thermal and moisture transmission behaviour of the worn clothing [2]. Clothing creates a microclimate between the skin and the environment, which supports the body's thermoregulatory system to keep its temperature within a safe range, even when the external environment temperature and humidity changes to quite an extent.[1]

\section{Components of clothing comfort}

Comfort is one of the most important aspects of clothing. Many attempts have been made to define comfort, but a satisfactory definition is yet to be obtained.

Comfort has been defined by many researchers in different ways.

- Comfort is influenced by the physiological reaction of the wearer.

- Comfort is temperature regulation of the body.

- Comfort is the absence of unpleasantness or discomfort.

- Comfort is a state of pleasant psychological, physiological and physical harmony between a human being and the environment. All three aspects are equally important, since people feel uncomfortable if any one of them is absent.

So, to know about the comfort characteristics of any particular fabric or clothing, it is required to determine the different properties of the fabric which have direct effects on the comfort. Broadly there are four basic elements of clothing comfort, namely thereto-physiological aspect, sensorial or tactile aspect, physiological aspect and fitting comfort.[1] The thereto-physiological comfort concerns about the heat and moisture transmission characteristics through clothing, i.e. transmission of heat, air, and moisture (liquid and vapour). The sensorial or tactile comfort is related with the mechanical contact of the fabric with skin, i.e. how a fabric or garment feels when it is worn 
next to the skin. These are fabric handle or feel, softness, fullness, warm-cool touch, static charge generation, flexing, pricking, itching, etc. The physiological comfort depends on the aesthetic properties of fabric, i.e. drape, lustre, colour, crease, pilling, staining, etc. The fitting comfort deals with the size and fit of clothing. All the above comfort aspects are strongly correlated between them. In clothing comfort, the most important factor is the movement of heat and moisture (liquid and vapour) through clothing to maintain the thermal equilibrium between human body and the environment. According to Goldman [7] there are four primary factors in clothing comfort, i.e. function, feel, fit and fashion. The function related to clothing comfort parameters are thermal and moisture (liquid and vapour) transmission, water absorbency, drying behaviour, etc. The thermal transmission is a linear function of fabric thickness and relatively independent of fibre characteristics. Thus, the thermal transmission can be controlled by the modification of yarn and fabric structures. Moisture vapour permeability also controls thermal characteristics by evaporative cooling phenomenon. The water transmission in liquid form, i.e. wicking, depends mainly on the type of fibre, weave structure of fabric and the finishes applied to the fabrics. The absorbency of water depends on fibre type, finishes, weave and design of fabric. Although the wicking is important, the amount of liquid that can be blotted away from the skin is also very important. The drying behaviour depends on the type of fibre, fabric and design of fabric. It is important because the ability of the body heat to rapidly dry clothing and restore insulation is a critical factor for survival. The clothing comfort related to feel are broadly divided into two distinct areas, namely the feel of clothing when held between the thumb and the fingers and the feel of clothing by the wearer when worn in contact with skin. Fit may incorporate factors from fashion, including concepts that may be diametrically opposed to comfort.[3]

\section{PSYCHOLOGY AND COMFORT}

2.1 Psycho-physiological factors of clothing comfort The physiological factors of human body for expressing the human comfort are average skin temperature, degree of skin wetness (indicated by electrical conductivity at the body surface), rate of sweating, the amount of sweat, sweat absorbed by clothing, and rate of heart beat. It is important to correlate all the physiological parameters with contributing psychological factors to predict the perceptions of comfort. Thermal effects contribute extensively to the 'comfort' of an individual, complex physiological and psychological factors collectively play an important role in defining this complex quality with reference to clothing [1]. In fact, clothing comfort is the psychological feeling of wearer who wears the clothing under different environmental conditions. The factors influencing the clothing comfort sensations of wearer can be divided broadly into three groups:

(i) physical factors (deals with the human-clothing-environment system);

(ii) psycho-physiological factors of the wearer,

(iii) psychological filters of the brain. The comfort status of wearer depends on all these factors and their complex interactions and synchronizations.

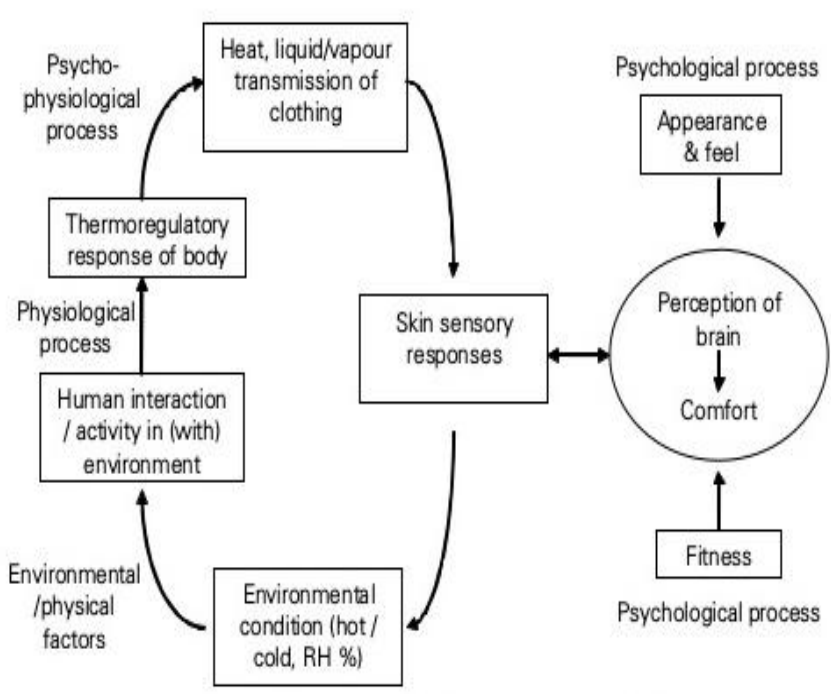

Figure-2

Figure 2 shows the interrelationships between the important physical and physiological factors those control the clothing comfort. The figure illustrates the process of how the subjective perception of overall comfort is formulated. The physical processes provide different signals or stimuli (e.g., warm/cool, touch, prick, pressure, wetness, etc.) to the sensory organs of the human body. The human body receives all these stimuli and subsequently generates neurophysiologic impulses. The neurophysiologic impulses are then sent to the brain to take corrective actions to adjust the sweating rate, blood flow, and sometimes heat production, shivering, etc. [2] The brain, after receiving the sensory impulses, processes all these impulses to generate the human subjective perception of various individual sensations, and further evaluate and 
weigh them based on the past experiences. The processes of evaluation and weighing are influenced by many factors such as physical, environmental, social, cultural, etc. The clothing comfort is a human psychological perception related with clothing ensemble, which is an outcome of complex linkages between individual sensory stimuli received by brain, evaluation and weighing of all these stimuli to formulate subjective perception of overall comfort based on wear experience.

\subsection{Psychological perceptions of clothing comfort}

The wearers consider the comfort as one of the most important attributes in their clothing ensembles, so there is a need to develop an in-depth scientific understanding of the psychological perception of clothing comfort sensations. The physical comfort is greatly influenced by tactile and thermal sensations arising from contact between skin and the immediate environment [3]. Comfort may be defined as pleasant state of physiological, psychological and physical harmony between a human being and the environment [4]. Comfort can also be defined as a holistic concept, which is a state of multiple interactions of physical, physiological, and psychological factors [5].All these definitions only identify the factors influencing the human psychological perceptions. Developed a linear model based on artificial neural network predictions using three major factors which affect the comfort perceptions, namely moisture related factor, tactile sensations and thermal-fit comfort, and their relative weights to predict overall comfort perceptions. They have developed feed-forward back-propagation neural network models to predict an overall comfort perception from ten individual sensory perceptions (clammy, clingy, damp, sticky, heavy, prickly, scratchy, fit, breathable and thermal). They have reported a good agreement between predicted and actual clothing comfort perceptions, which indicated that the neural network is an effective technique for modelling the psychological perceptions of clothing sensory comfort They have further reported that the functions and interrelationships of individual sensory perceptions and comfort are unknown. [9]

\subsection{Psychological aspects of aesthetic comfort}

The physical attributes of the human body are directly related to the aesthetic comfort characteristics of clothing. A large number of researchers [7] have studied the complex interplay between clothing aesthetics and body attributes and the human body has been designated as the central element in the aesthetic experience of clothing. The relationships between the aesthetics of clothing and the physical attributes of the body is not the matter of only textile and clothing discipline but many other fields of research, like physical and demographic attributes affecting aesthetics, social aspect, psychological, cultural aspects that influence the aesthetic experience, etc. The researchers have taken into account of all these factors in their studies on clothing aesthetics. Human body imaging technique may be adopted in the study of clothing aesthetics. The clothing not only creates a person's appearance but also provide aesthetic pleasure to the person through the wearing experience. The wearers generally try to achieve the aesthetic pleasure through their clothing by emphasizing certain positive features of their bodies through their clothing and hiding other negative features. Therefore, aesthetic attributes in clothing helps to minimize the differences between cultural beauty concepts and their perceived appearance, which helps to improve self-image and have stronger self-esteem of a person [8].

\section{FUTURE TRENDS}

Clothing comfort has been identified as one of the key attributes in consumers' perception of the desirability of apparel products in all markets. Despite the extensive research in the area of comfort perception and clothing, there are still uncertainties with regard to fabric or garment design. Requirements of consumers are changing along with products and wear situations. In a highly competitive textile and apparel market, in order to succeed in the market place, the market players have to meet or even exceed consumers' needs and expectations.

In this chapter, tactile and thermal related factors affecting human comfort status were discussed and predicting models were briefly reviewed. Also, a new approach to characterizing comfort was described. The comfort phenomenon is typically described by hundreds of parameters. However, this approach is based on using a single index of comfort expressed by the ratio between the actual area of fabric/skin contact and the corresponding apparent area. Extensive analysis showed that this index correlates extremely well with all main aspects of comfort, namely psychological, thermophysiological, and neurophysiological.

Clothing comfort is expected to continue to interest researchers of different sectors of the textile/apparel market and the subjective nature of 
this phenomenon will probably remain an essential aspect of research and implementation. This is primarily due to the critical importance of human judgment, which is highly variable and often psychologically driven. Unfortunately, subjective evaluation does not yield precise design guidelines except for extreme conditions. It is our opinion that an objective comfort evaluation coupled with subjective assessment seems to be the appropriate approach.

\section{REFERENCES}

[1] http://ashrae.org/about-ashrae/

[2] Hes, L.,Thermal comfort properties of textile fabrics in wet state, in Proc. Izmir Internat. Textile and Apparel Symposium 2007: Cesme (Turkey).

[3] http://www.scribd.com/doc/30439784/Introduction-to-ClothingComfort

[4] Celcar, D., H. Meinander, and J. Gers`ak,Heat and moisture transmission properties of clothing systems evaluated by using a sweating thermal manikin under different environmental conditions. International Journal of Clothing Science and Technology, 2008.20(4):240-252.

[5] OLSCHEWSKI H AND BRUCK K., 'Cardiovascular and muscular factors related to exercise after pre-cooling', J Appl. Physiol. 64, 803-811, 1988.

[6] GOLDMAN R.F., 'The four 'Fs' of clothing comfort', Elsevier Ergonomics Book Series-Environmental Ergonomics

[7] The clothing fashion is related with the psychological comfort.

[8] Rudd N A., Lennon S J., 'Body image- linkage aesthetics and social psychology of appearance, clothing and tect. Res.J.19,120-133, 2001

[9] Clothing and aesthetic experience, Advancing multi-diciplinary perspective, Intl Text and apparel Assoc. 97, 1994 